\title{
Comparative study between fascia lata and temporalis fascia in myringoplasty
}

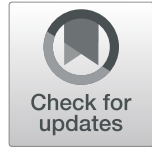

Ayman Ali Abdel Fattah, Abdel Hay Rashad Elasy, Ahmed Helmy Hoseini ${ }^{*}$ and Tarek Abdel Rahman Abdel Hafez

\begin{abstract}
Background: Repair of a perforated tympanic membrane (myringoplasty) can facilitate normal middle ear function, resist infection, and help re-establish normal hearing. Autogenous graft materials are the most popular graft materials used in myringoplasty because of their easy acceptability by the body. This study is conducted to compare between temporalis fascia graft and fascia lata graft in myringoplasty for patients with tubo-tympanic dry perforation.

Results: A total of 60 patients with persistent dry tympanic membrane perforation were included in our study during the period from January 2018 to May 2020. Patients underwent myringoplasty with temporalis fascia (30 patients as group A) or fascia lata (30 patients as group B). Patients were scheduled for follow-up visits concerning graft status, ear discharge, and audiograms. The mean postoperative air-bone gap in group A was $17.5 \pm 4$ after 1 month and $8.6 \pm 6.9$ after 3 months, while in group B, the mean postoperative air-bone gap was $17.6 \pm 4.9$ after 1 month and $9.4 \pm 7.5$ after 3 months. There was $90 \%$ success in graft uptake in group A, while there was $80 \%$ success in group $B$.

Conclusion: Using temporalis fascia is still the best and most trustworthy technique of myringoplasty compared to fascia lata graft. However, fascia lata can be a good alternative to temporalis fascia especially in cases of revision myringoplasty, ears having large perforation, or near-total perforation where the chances of residual perforation are high because of the limited margin of remnant tympanic membrane overlapping the graft.
\end{abstract}

Keywords: Fascia lata, Temporalis fascia, Myringoplasty

\section{Background}

The purpose of closing chronic dry perforations of the tympanic membrane is to improve hearing and prevent middle ear infections. Closure of the perforation isolates the middle ear from the external environment and prevents contamination by exposure to pathogens and restores the vibratory area of the tympanic membrane [1]. Skin grafts were the first graft materials used in myringoplasty by Horst Wullstein and Fritz Zollner [2, 3]. However, they were discontinued from use because of high failure rates and the formation of cholesteatoma [4]. Xenografts such as porcine dura and calf jugular vein were used to repair tympanic membrane perforations but were quickly abandoned because of their very high failure rates [5].

* Correspondence: ahmed.helmy.hoseini@gmail.com

Department of Otorhinolaryngology, Menoufia University, Menoufia, Egypt
Autogenous graft materials are the most popular graft materials used in myringoplasty because of their easy acceptability by the body. Connective tissues like fascia lata, dura, temporalis fascia, and vein graft and perichondrium are preferable because they are easier to handle and more resistant to infection, and the problem of cholesteatoma formation is much less [6]. Such an abundance of materials implies that there is no clear-cut favorite and the choice of graft material depends on the individual surgeon's preference. Due to its anatomic proximity, translucency, and suppleness, temporalis fascia is the most preferred grafting materials among the otologists and successful closure is anticipated in approximately $90 \%$ of primary myringoplasty [7].

Fascia lata is a fibrous sheath that encircles the thigh subcutaneously. In 1999, preserved mashed fascia lata 
became approved as a tissue product designed to replace areas of lost fascia or collagen [8]. In the selection of graft tissue, several factors are considered including the biological properties, probability of survival, adequacy in size, and ease of procurement [9]. Graft displacement, improper placement, infection, hemorrhage, and Eustachian tube dysfunction are the known contributing factors for the failure of closure of perforation. Thus, consistent achievement of good results in myringoplasties is still a challenge and one of the most difficult tasks of otology surgery [6]. This study aimed to compare temporalis fascia graft versus fascia lata graft in myringoplasty for patients with tubo-tympanic dry perforation.

\section{Methods}

This prospective randomized controlled trial was conducted from January 2018 to May 2020 after the approval of the ethical committee of the hospital. This study was conducted on patients diagnosed with uncomplicated tubo-tympanic chronic suppurative otitis media selected from the outpatient clinics. Inclusion criteria included patients between the age group of 10-60 years with uncomplicated mucosal chronic otitis media and patients with dry perforation for at least 6 weeks before surgery. Exclusion criteria were age groups below 10 years or above 60 years, patients with a previous history of ear surgery, patients with sensorineural hearing loss or mixed hearing loss, or patients with squamous chronic otitis media.

Sixty patients were included and were divided randomly into 2 groups as temporalis fascia graft was used in group A and fascia lata graft was used in group B. All patients were fully informed about the randomization. All the patients were subjected to detailed otorhinolaryngological examination followed by pure tone audiometry, tympanometry with Eustachian tube function, computerized tomography of the temporal bone, and routine hematological and biochemical investigations.

Patients of both groups underwent myringoplasty under general anesthesia using postaural approach which facilitates a large area of tympanic annulus exposure for placing graft with underlay technique. Also when using temporal fascia graft, a single incision approach can help in harvesting the graft. For harvesting fascia lata graft, an incision was made at the junction of the middle and upper $1 / 3$ of the lateral part of the thigh after giving local anesthesia. An incision about $5 \mathrm{~mm}$ away from the postauricular groove was made, and dissection was done till the bone was reached. The spine of Henle is palpated, and the posterior wall of the external auditory canal was dissected in a way to expose the tympanic annulus. The rim of the annulus was freshened by a sickle knife. A tympanic meatal flap was raised, and the middle ear cavity is examined for ossicular mobility. The pre-dried graft (either temporal fascia or fascia lata) was then placed under the annulus after filling the middle ear cavity by gel foam. The gel foam keeps the graft in place and helps in early take-up. The tympanomeatal flap was replaced back, and the external auditory canal was packed with antibiotic ointment soaked gauge piece.

Outcomes measured were success rate and hearing improvement. This was done by an independent professional who was unaware of the randomization. Pure tone audiometry and tympanometry were performed at the end of the first and the third month for all the patients.

\section{Statistical analysis}

After collecting the data, the statistical analysis was performed using Excel 2017 and SPSS software (version 15.0, SPSS, Inc., Chicago, IL). The categorical variables were compared using a chi-square test. $P$ values of 0.05 were considered to be statistically significant based on the Bonferroni correction.

\section{Results}

A total of 30 patients were considered in every group of this study. The mean age of patients was 28.4 years, $56.7 \%$ of cases were male, and $43.3 \%$ were female. Forty percent of patients had a perforation of the right tympanic membrane, and $60 \%$ of patients had a perforation of the left tympanic membrane (Table 1).

There was a non-statistically significant difference among studied groups according to the site, size, or shape of perforation (Table 2).

There was $90 \%$ success in graft uptake in group A while there was $80 \%$ success in group B with a nonstatistical significant difference between results of graft uptake between both groups (Table 3).

Regarding the relation between the size of the perforation and the success rate, group A had 100\% graft uptake success in patients with medium-sized perforation of the tympanic membrane, $71.4 \%$ success in patients with large perforation, and $66.7 \%$ success in patients with subtotal perforation, while group B had 83.3\% graft uptake success in patients with medium-

Table 1 Epidemiological study of study cases

\begin{tabular}{llc}
\hline Variables & \multicolumn{2}{l}{ Patients with CSOM $=60$} \\
\hline Age (years), mean \pm SD & \multicolumn{2}{l}{$10-55$ years old, 28.4 \pm 9.8} \\
& No. & $\%$ \\
Gender & 26 & 43.3 \\
$\quad$ Female & 34 & 56.7 \\
$\quad$ Male & & \\
Side of perforation & 24 & 40 \\
$\quad$ Right & 36 & 60 \\
Left & &
\end{tabular}


Table 2 Comparison between both study groups regarding criteria of the perforation

\begin{tabular}{|c|c|c|c|c|c|c|c|}
\hline \multirow[t]{3}{*}{ Parameter } & & \multicolumn{4}{|c|}{ No. of CSOM cases $=60$} & \multirow[t]{3}{*}{$x^{2}$ test } & \multirow[t]{3}{*}{$P$ value } \\
\hline & & \multicolumn{2}{|c|}{ Group A, no. $=30$} & \multicolumn{2}{|c|}{ Group B, no. $=30$} & & \\
\hline & & No. & $\%$ & No. & $\%$ & & \\
\hline \multirow[t]{3}{*}{ Site of perforation } & Central part of TM in pars tensa & 18 & 60 & 10 & 33.3 & \multirow[t]{3}{*}{4.705} & \multirow[t]{3}{*}{0.319 NS } \\
\hline & Antero-inferior part of TM in pars tensa & 7 & 23.3 & 12 & 40 & & \\
\hline & Postero-inferior part of TM in pars tensa & 5 & 16.7 & 8 & 26.7 & & \\
\hline \multirow[t]{3}{*}{ Shape of perforation } & Rounded shaped & 9 & 30 & 14 & 46.7 & \multirow[t]{3}{*}{2.865} & \multirow[t]{3}{*}{0.581} \\
\hline & Oval shaped & 14 & 46.7 & 12 & 40 & & \\
\hline & Kidney shaped & 7 & 23.3 & 4 & 13.3 & & \\
\hline \multirow[t]{3}{*}{ Size of the perforation } & Medium sized & 20 & 66.7 & 18 & 60 & \multirow[t]{3}{*}{2.865} & \multirow[t]{3}{*}{0.581} \\
\hline & Large & 7 & 23.3 & 10 & 33.3 & & \\
\hline & Subtotal & 3 & 10 & 2 & 6.7 & & \\
\hline
\end{tabular}

$X^{2}$ chi-square test, NS non-significant $(P$ value $>0.05), S$ significant $(P$ value $\leq 0.05), H S$ highly significant $(P$ value $\leq 0.001)$

sized perforation of the tympanic membrane, $80 \%$ success in patients with large perforation, and $100 \%$ success in patients with subtotal perforation. There was a nonstatistically significant difference between results of graft uptake among different perforation sizes of both studied groups (Table 4).

The mean preoperative air-bone gap was $34.6 \pm 6.7 \mathrm{~dB}$ in group A and $35.3 \pm 6.4 \mathrm{~dB}$ in group B with no statistically significant difference among studied groups. Postoperative air-bone gap in group A was $17.5 \pm 4 \mathrm{~dB}$ after 1 month and $8.6 \pm 6.9 \mathrm{~dB}$ after 3 months, while in group $\mathrm{B}$, the mean postoperative air-bone gap was $17.6 \pm 4.9$ $\mathrm{dB}$ after 1 month and $9.4 \pm 7.5 \mathrm{~dB}$ after 3 months. There was no statistically significant difference among studied groups regarding the postoperative air-bone gap after 1 and 3 months (Table 5).

The mean operative duration in group A was $46.5 \pm$ 12.7 min, while in group B, it is $59.8 \pm 9.2$ with a statistically significant difference between both groups ( $P$ value $=0.039)$ (Table 6).

\section{Discussion}

Surgical repair of the tympanic membrane and tympanic membrane grafting has traveled a long way since the time of Berthold [10] who coined the term

Table 3 Comparison of graft uptake results among study

groups

\begin{tabular}{llllll}
\hline Graft uptake & \multicolumn{2}{l}{ Cases with graft failure $=\mathbf{9}$} & $\begin{array}{l}\chi^{2} \\
\text { test }\end{array}$ & $P$ value \\
\cline { 3 - 6 } & & No. & $\%$ & 4.074 & 0.396 NS \\
\hline Group A & Uptake & 27 & 90 & & \\
& Failed & 3 & 10 & & \\
Group B & Uptake & 24 & 80 & & \\
& Failed & 6 & 20 & & \\
\hline
\end{tabular}

$X^{2}$ chi-square test, NS non-significant ( $P$ value $\left.>0.05\right), S$ significant $(P$ value $\leq$ $0.05)$, HS highly significant $(P$ value $\leq 0.001)$ "myringoplasty" [11]. These years have been filled with numerous technical advances that have improved surgery for tympanic membrane repair to a high level of accuracy. A critical problem early in the development of tympanoplasty was finding a suitable material for tympanic membrane grafting. This evolution of the tympanic membrane grafting has been based on biological tissues of mesodermal origin which contain collagen matrix [12].

Many autologous graft materials such as temporalis fascia, tragal perichondrium, cartilage, fat, and fascia lata have been used in repairing tympanic membrane perforations [6]. Various studies have been done comparing different graft materials and techniques. The main aim of utilizing different autografts in the study was to evaluate and compare the anatomic and functional results of various autografts.

Due to its anatomic proximity, translucency, and suppleness, temporalis fascia is the most preferred grafting materials among the otologists and successful closure is anticipated in approximately $90 \%$ of primary tympanoplasty [7]. Temporalis fascia is easy to harvest, and it can be used as an overlay or underlay graft for

Table 4 Assessment of graft uptake success/failure with respect to size of perforation

\begin{tabular}{|c|c|c|c|c|c|c|c|}
\hline \multirow{2}{*}{$\begin{array}{l}\text { Size of } \\
\text { perforation }\end{array}$} & \multirow[t]{2}{*}{ Group } & \multicolumn{2}{|c|}{ Success } & \multicolumn{2}{|c|}{ Failure } & \multirow{2}{*}{$\begin{array}{l}\text { Total } \\
\text { no. }\end{array}$} & \multirow{2}{*}{$\begin{array}{l}P \\
\text { value }\end{array}$} \\
\hline & & No. & $\%$ & No. & $\%$ & & \\
\hline \multirow[t]{2}{*}{ Medium sized } & Group A & 20 & 100 & 0 & 0 & 20 & 0.37 \\
\hline & Group B & 15 & 83.3 & 3 & 16.7 & 18 & \\
\hline \multirow[t]{2}{*}{ Large } & Group A & 5 & 71.4 & 2 & 28.6 & 7 & 0.731 \\
\hline & Group B & 8 & 80 & 2 & 20 & 10 & \\
\hline \multirow[t]{2}{*}{ Subtotal } & Group A & 2 & 66.7 & 1 & 33.3 & 3 & 0.3378 \\
\hline & Group B & 2 & 100 & 0 & 0 & 2 & \\
\hline
\end{tabular}

$X^{2}$ chi-square test, $N S$ non-significant $(P$ value $>0.05), S$ significant $(P$ value $\leq$ $0.05)$, HS highly significant $(P$ value $\leq 0.001)$ 
Table 5 Preoperative and postoperative air-bone gap (ABG) at 1 and 3 months in both study groups

\begin{tabular}{lllll}
\hline ABG & Mean \pm SD & t test & & \\
\cline { 2 - 4 } & Group A & Group B & 0.379 & 0.710 \\
\hline Preoperative ABG & $34.6 \pm 6.7$ & $35.3 \pm 6.4$ & 0.029 & $0.997 \mathrm{HS}$ \\
Postoperative ABG after 1 month & $17.5 \pm 4$ & $17.6 \pm 4.9$ & 0.457 & $0.654 \mathrm{HS}$ \\
Postoperative ABG after 3 months & $8.6 \pm 6.9$ & $9.4 \pm 7.5$ & & \\
\hline
\end{tabular}

$A B G$ air-bone gap, NS non-significant ( $P$ value $>0.05)$, $S$ significant $(P$ value $\leq 0.05)$, HS highly significant $(P$ value $\leq 0.001)$

primary operations as there are no size limitations. Temporalis fascia also has a certain advantage of being similar in structure to the missing tunica propria of the drum. Although there are high success rates with temporalis fascia graft, poor results may be obtained in the late postoperative period, and in case of perforations in anterior and wide perforations. The cause of the failure is attributed to a lack of elasticity and decreased resistance to pressure changes in the middle ear and external ear [13].

The use of fascia lata as a graft material in myringoplasty was reported to have better dimensional stability and subsequently leads to a better outcome, particularly with respect to achieving an intact tympanic membrane and hearing improvement [14]. Fascia lata is thicker and stiffer than temporalis fascia. It is easier to manipulate in the middle ear as it does not get folded on itself and thus has better handling qualities.

Our study is a comparative observational (cohort) prospective study carried on 60 patients (60 ears) diagnosed to have an uncomplicated tubo-tympanic type of chronic suppurative otitis media who underwent myringoplasty. In 30 patients, temporalis fascia was used as a graft material (group A), and in 30 patients, fascia lata was used as a graft material (group B). Both groups were matched with no statistically significant difference among studied groups according to shape, size, or site of perforation.

The overall graft uptake success rate of fascia lata graft in our study was $80 \%$ which is comparable with Patil et al. (85\%) [15]. However, it was lower than the study of Indorewala et al. (96\%) and Verma et. al. (92\%) $[8,16]$.

The temporalis fascia had an overall graft uptake success rate of $90 \%$ which is lower than the study conducted by Verma et al. (96\%) and Indorewala et al. (95\%) $[8,16]$. But Dabholkar et al. in underlay tympanoplasty achieved a graft success rate of $84 \%$ for temporalis fascia

Table 6 Comparison of operative duration among study groups

\begin{tabular}{llll}
\hline & $\begin{array}{l}\text { Duration of the operation } \\
\text { in minutes }( \pm \text { SD) }\end{array}$ & $\boldsymbol{t}$ test & $\boldsymbol{P}$ value \\
\hline Group A & $46.4 \pm 6$ & 2.169 & $0.044 \mathrm{~S}$ \\
Group B & $49.6 \pm 6.2$ & & \\
\hline
\end{tabular}

$X^{2}$ chi-square test, NS non-significant ( $P$ value $\left.>0.05\right), S$ significant $(P$ value $\leq$ $0.05)$, HS highly significant $(P$ value $\leq 0.001)$
[17]. However, the difference in graft success rate between the two groups of our study was not statistically significant. Thus, our results suggest that type of graft material does not influence the successful graft take-up.

The study of surgical outcome for these graft materials with respect to the size of the perforation showed that the success rate in group A decreased from $100 \%$ in patients with medium-sized perforation to $71.4 \%$ in patients with large perforation and $66.7 \%$ in patients with subtotal perforation. On the other hand, the success rate in group B decreased from $83.3 \%$ in patients with medium-sized perforation of the tympanic membrane to $80 \%$ in patients with large perforation. However, it reached $100 \%$ success in patients with subtotal perforation. A non-significant association was observed between the graft success in both groups and the size of perforation revealing that the successful graft take-up with respect to graft materials does not depend on the size of the perforation.

Hearing in our study was judged pre- and postoperatively by pure tone audiometry. The mean preprocedure ABG was $34.6 \pm 6.7 \mathrm{~dB}$ in group A (temporalis fascia graft myringoplasty) and $35.3 \pm 6.4$ in group B (fascia lata graft myringoplasty).

Postoperatively, the mean postoperative ABG in group A was $17.5 \pm 4 \mathrm{~dB}$ after 1 month and $8.6 \pm 6.9$ after 3 months, while in group $\mathrm{B}$, the mean postoperative ABG was $17.6 \pm 4.9$ after 1 month and $9.4 \pm 7.5$ after 3 months. There was no statistically significant difference among studied groups regarding the pre- or postoperative air-bone gap.

In the study conducted by Verma et al., audiological closure of the air-bone gap in the range of $0-30 \mathrm{~dB}$ was achieved in $88 \%$ cases of temporal fascia and $80 \%$ in fascia lata after surgery with no significant difference [16]. In 2014, Patil et al. found that the mean gain in airbone gap postoperatively for temporalis fascia was 9.36 $\mathrm{dB}$ and for fascia lata was $12.1 \mathrm{~dB}$ which also was not significant [15].

The duration of the operation is an important parameter in terms of the duration of anesthesia, the surgeon's concentration, and the increased risk of iatrogenic complications. In our study, myringoplasty done using fascia lata took more time than temporalis fascia with a statistically significant difference. 


\section{Conclusion}

Although temporalis fascia had better overall graft uptake success and air-bone gap closure, it was statistically non-significant. The operative duration was significantly less using temporalis fascia than fascia lata. Using temporalis fascia is more simple due to anatomic proximity, and only single incision is needed; however, fascia lata had better dimensional stability and it was easier to handle and manipulate in the middle ear compared to temporalis fascia because of its physical characteristics and texture. So, fascia lata can be a good alternative to temporalis fascia especially in cases of revision myringoplasty, ears having large perforation, or near-total perforation where the chances of residual perforation are high because of the limited margin of remnant tympanic membrane overlapping the graft.

\section{Acknowledgements}

Not applicable

\section{Authors' contributions}

All operations were done by $A A$ and $T A$ and observed by $A H . A E, A H$, and TA shared in the data collection and interpretation of the results. AE and AA were major contributors in writing the manuscript. All authors finally read and approved the final manuscript.

\section{Funding}

None

\section{Availability of data and materials}

The datasets used and/or analyzed in the current study are available from the corresponding author on reasonable request.

\section{Ethics approval and consent to participate}

An informed written consent to participate in the study was provided by all participants and the parent or legal guardian in the case of children under 16 before operation and before investigations according to the Research Ethics Committee of the Faculty of Medicine, Menoufia University. Ethics committee reference number is 12/2017ENT/639.

\section{Consent for publication}

Not applicable

\section{Competing interests}

The authors declare that they have no competing interests.

Received: 10 July 2020 Accepted: 12 October 2020

Published online: 04 November 2020

\section{References}

1. Naderpour M, Shahidi N, Hemmatjoo T (2016) Comparison of tympanoplasty results in dry and wet ears. Iran J Otorhinolaryngol 28(86): 209-214

2. Wullstein $\mathrm{H}$ (1956) Theory and practice of tympanoplasty. Laryngoscope 66: 1076-93

3. Zöllner $F(1955)$ The principles of plastic surgery on the soundconducting apparatus. J Laryngol Otol 69:637-52

4. Chhapola S, Matta I (2012) Cartilage-perichondrium: an ideal graft material? Indian Journal of Otolaryngology and Head \& Neck Surgery 64(3):208-213

5. Spiros Manolidis. Closure of tympanic membrane perforations in Glosscock - Shambaugh Surgery of the ear, Hamilton, Ontario, 2003; 400-418.

6. Roychaudhuri BK (2004) 3-flap tympanoplasty-a simple and sure success technique. Indian J Otolaryngol Head Neck Surg 56:196-200

7. Onal K, Arslanoglu S, Songu M, Demiray U, Demirpehlivan IA (2012) Functional results of temporalis fascia versus cartilage tympanoplasty in patients with bilateral chronic otitis media. J Laryngol Otol 126(1):22-25
8. Indorewala S, Adedeji TO, Indorewala A, Nemade G (2015) Tympanoplasty outcomes: a review of 789 cases. Iran J Otorhinolaryngol 27(79):101-108

9. Murugendrappa MA, Siddapa PN, Shambhulingegowda A, Basavaraj GP (2016) Comparative study of two different myringoplasty techniques in mucosal type of chronic otitis media. J Cin Diag Res 10(2):MC01-MC03

10. Palva T, Virtanen H (1982) Pitfalls in myringoplasty. Acta Otolaryngol 93:441

11. Sarker MZ, Ahmed M, Patwary K, Islam R, Joarder AH (2011) Factors affecting surgical outcome of myringoplasty. Bangladesh Journal of Otorhinolaryngology 17(2):82-87

12. Booth JB (1973) Myringoplasty - factors affecting results. Final report J Laryngolotol 87:1039-1084

13. Dornhoffer J (2003) Cartilage tympanoplasty: indications, techniques, and outcomes in a 1,000-patient series. Laryngoscope 113(11):1844-1856

14. Sprem N, Branica S, Dawidowsky K (2001) Tympanoplasty after war blast lesions of the eardrum: retrospective study. Croat Med J 42:642-645

15. Patil K, Baisakhiya N, Deshmukh PT (2014) Evaluation of different graft material in type 1 tympanoplasty. Indian J Otol 20:106-114

16. Verma S, Arora A, Narvey VP (2019) Comparison of conventional temporalis fascia myringoplasty with fascia lata myringoplasty among patients with hearing loss. Int J Otorhinolaryngol Head Neck Surg 5:926-931

17. Dabholkar JP, Vora K, Sikdar A (2007) Comparative study of underlay tympanoplasty with temporalis fascia and tragal perichondrium. Indian J Otolaryngol Head Neck Surg 59:116-119

\section{Publisher's Note}

Springer Nature remains neutral with regard to jurisdictional claims in published maps and institutional affiliations.

\section{Submit your manuscript to a SpringerOpen ${ }^{\circ}$ journal and benefit from:}

- Convenient online submission

- Rigorous peer review

- Open access: articles freely available online

- High visibility within the field

- Retaining the copyright to your article

Submit your next manuscript at $\boldsymbol{\nabla}$ springeropen.com 